\title{
Iberian World Empires and the Globalization of Europe 1415-1668
}

Yun-Casalilla, Bartolomé (2019).

Singapur: Palgrave Macmillan, 520 páginas.

\section{\$ Martín L. E. Wasserman \\ Instituto de Historia Argentina y Americana "Dr. Emilio Ravignani"-UBA/Conicet, Argentina.}

La obra de Bartolomé Yun-Casalilla se propone el desafiante objetivo de comprender las relaciones entre la globalización y los imperios antes del siglo XIX. Un ciclópeo propósito que la obra afronta con solidez y claridad a lo largo de sus ocho capítulos, agrupados en tres partes que organizan al libro y le confieren una amena legibilidad. En ellos, el autor coloca a los imperios ibéricos en el centro -y ya no en la periferia- de la temprana globalización, discutiendo algunos de los principales estereotipos arraigados en la caracterización sobre la sociedad y la economía ibéricas durante la modernidad temprana, mediante un minucioso análisis que conecta distintos niveles de la realidad social, económica, política y cultural.

La obra ofrece una caracterización pormenorizada sobre los procesos económicos, políticos y sociales que colocaron a los imperios ibéricos al frente de una primera globalización europea durante la temprana modernidad. Para ello, el libro recorre un arco cronológico de largo plazo que comienza en 1415 y finaliza en 1668: desde la conquista de Ceuta, que expresaba a un mismo tiempo el inicio de la expansión ibérica más allá de sus costas y los primeros síntomas de recuperación de la crisis del siglo XIV, hasta la definitiva separación de las coronas de Castilla y Portugal con el Tratado de Lisboa, que ponía fin a la guerra de secesión portuguesa iniciada en 1640 y marcaba el fin de la unidad política sostenida desde 1580. Un recorrido de imponentes magnitudes que el autor vuelve transitable gracias a una minuciosa explicación, en la que logra conjugar la escala global con la local, desafiando modelos interpretativos establecidos y proponiendo claves de explicación alternativas.

El libro de Yun-Casalilla sugiere tres bloques históricos para comprender el proceso que hizo de las sociedades ibéricas los motores de la expansión europea y de una primera globalización, apuntalada en la creciente interconexión de intercambios mercantiles que serían decisivos para la construcción de espacios económicos a través de los cuales movilizar la transferencia de recursos entre Europa y sus dominios ultramarinos (Yun-Casalilla, 2019: 145). Un primer período, que comienza con la salida de la crisis del siglo XIV y concluye con la inflexión de 1521, permite comprender que las sociedades medievales se encontraban sujetas a una dinámica de tensiones internas entre sus élites que impulsó la necesidad de obtener mayores recursos por la vía expansiva, y cuya inestabilidad política pudo resolverse mediante coaliciones dominantes que consolidaron un sistema político distintivamente ibérico: monarquías que, aún incapacitadas para imponer una forma irrestricta de absolutismo, lograron emplear la guerra y el crecimiento económico para negociar con las élites una estabilidad política durable (Yun-Casalilla, 2019: 28, 35). Castilla y Portugal lograban así atenuar las tensiones internas y expandirse para establecer sus respectivos imperios, sobre una estabilidad endeble cuyos límites habrían de expresare en las rebeliones de las Germanías y de las Comunidades hacia 1519-1521. Se abría así un segundo período, en el cual el desarrollo de una monarquía compuesta global lograría incidir sobre las tensiones sociales estructurales inherentes a las élites peninsulares (Yun-Casalilla, 2019: 155). El crecimiento experimentado durante el siglo XVI demostraba que CastiIla y sus recursos americanos se convertían en la columna vertebral del imperio de la dinastía Habsburgo y en el sostén de los recursos para la guerra (Yun-Casalilla, 2019: 162-163). Y aún con sus efectos inflacionarios corrosivos, la plata americana y la reconfiguración de la administración financiera del erario darían lugar a una nueva estabilidad institucional (Yun-Casalilla, 2019: 187). El inicio del gobierno de Felipe III hacia 1598 abriría entonces un tercer período, durante el cual las diferentes unidades políticas que constituían la monarquía compuesta de los 
Habsburgo afrontarían los desafíos que la globalización imponía al mantenimiento de su unidad (Yun-Casalilla, 2019: 270). El siglo XVII testimoniaría entre tanto la agudización del ciclo malthusiano en Europa (que condujo a desacelerar los impulsos de crecimiento agrario y urbano experimentados durante el siglo XVI), ante el cual Castilla se encontró en desventaja frente a otras potencias europeas como Inglaterra, Francia, las Provincias Unidas o Italia, que tuvieron la capacidad de aprovechar más eficientemente su inserción en el esquema global; en ese contexto, Castilla no lograría direccionar hacia sus arcas el crecimiento económico que América experimentó hasta mediados del siglo XVII (Yun-Casalilla, 2019: 311, 367).

A través de estos tres períodos, el libro explica que la creación de los imperios ibéricos, y el proceso de globalización que protagonizaron, constituyeron un medio para afrontar la consolidación de las élites y articular una negociación cambiante con éstas, incidiendo en mutaciones institucionales y en los patrones de desempeño económico (Yun-Casalilla, 2019: 152). Una negociación que desde 1600 se demostró incapaz para fomentar el crecimiento económico en la Península, toda vez que fortaleció la capacidad de las élites para absorber recursos antes que para retroalimentar con ellos la innovación y el crecimiento de la economía doméstica (Yun-Casalilla, 2019: 444-445). Desde la segunda mitad del siglo XVII los sistemas ibéricos consistieron en élites enriquecidas, gobiernos débiles y economías que encontraban dificultades para expandirse, mientras que otras potencias como Inglaterra comenzaron a desarrollar instituciones formales más eficientes en la protección de sus mercados (Yun-Casalilla, 2019: 448). Con ello, los imperios ibéricos no lograron conservar durante el siglo XVII la primacía que tuvieron durante el XVI en el sistema global cuya creación dinamizaron.

En cuanto al abordaje de los diseños institucionales que caracterizaron a los imperios ibéricos y a las formaciones políticas del período, Yun-Casalilla advierte la importancia central de instituciones implícitas o no siempre formalizadas jurídicamente (a las que propone denominar informales), sostenidas sobre reglas personales y apoyadas en la familia, las relaciones de afinidad, el patronazgo, la amistad, la reciprocidad o el prestigio. En ellas se apoyaba la organización política y la economía política, así como los principales mecanismos que regulaban la asignación de recursos. Esto ratifica la dificultad de distinguir ente instituciones formales e informales, en acuerdo con lo sugerido por Regina Grafe, en lo que puede identificarse como correlato de la porosa demarcación entre lo público y lo privado en sociedades de Antiguo Régimen (Yun-Casalilla, 2019: XXV). Este es, por lo tanto, un elemento central para comprender los modos en los cuales los marcos institucionales afectaron la asignación de recursos e incidieron en el crecimiento económico o en la recesión. De esta manera, y a diferencia de los postulados del nuevo institucionalismo económico, la expansión económica que tuvo lugar en los reinos ibéricos durante el siglo XVI prescindió de la definición de unos derechos de propiedad exclusivos: la propiedad comunal, combinada con la regulación de los concejos o en un contexto de abundante tierra, podía tener un efecto positivo para la expansión agraria (YunCasalilla, 2019: 141-142). Entre tanto, la movilización de recursos entre escenarios distantes estaba en manos de redes interpersonales de banqueros y comerciantes, desplegadas en el seno del complejo político de la monarquía compuesta y constituidas primordialmente por familias germanas y luego genovesas, que garantizaban la disponibilidad de recursos en los teatros de guerra a cambio no sólo de beneficios económicos sino de capital social y político (Yun-Casalilla, 2019: 166).

El autor explica con detenimiento la lógica con la que operaban estas instituciones desplegadas por la familia, las relaciones parentales, clientelares o de patronazgo: una economía de la legitimación que habilitaba la canalización del patrimonio de maneras habitualmente identificadas como antieconómicas, irracionales o, aún, como una "traición de la burguesía" (tal como la definiese Braudel) (Yun-Casalilla, 2019: 213). Yun-Casalilla explica con claridad la racionalidad que subyace a estos comportamientos, sólo comprensibles mediante su inserción en una cultura en la cual la obtención de capital político constituía un medio necesario para la promoción social, lo cual implicaba el empleo del capital económico en la construcción de redes de recursos relacionales. ${ }^{1}$ Sólo teniendo en consideración esa dimensión no explicitada del contexto institucional "formal" es posible calibrar el

1 En efecto, una creciente capacidad del rey para regular las relaciones dentro de la nobleza (gracias, favores, acuerdos crediticios) habría vuelto aún más necesaria la herramienta de los recursos políticos. Yun-Casalilla (2019: 229). 
rol de la ley oficial y de las instituciones jurídicamente formalizadas (Yun-Casalilla, 2019: 214-215). La racionalidad económica de los actores y el accionar de aquellas instituciones "informales" se encontraban orientadas, así, por la necesaria reconversión del capital entre sus distintas formas, en una interpretación que aproxima al autor a la matriz explicativa de Pierre Bourdieu.

Esta medular importancia de instituciones y organizaciones que el autor denomina "informales" condujo, por lo tanto, a una administración militar caracterizada por la descentralización, que redundaría en el largo plazo en un pobre desempeño defensivo y en fraudes articulados por las autoridades locales (Yun-Casalilla, 2019: 197198). La resolución de los conflictos internos no derivó, de este modo, en la creación de un estado fiscal-militar centralizado, lo cual representa otro desafío del libro a las claves de interpretación historiográfica establecidas (Yun-Casalilla, 2019: 155). ${ }^{2}$

La descentralización de los recursos para la guerra retroalimentaría así el poder de las élites desde 1580, un elemento sólo comprensible en la medida en que se advierta la importancia de las instituciones implícitas o "informales" como puntales del desempeño económico (Yun-Casalilla, 2019: 209, 212). ${ }^{3}$ Descentralización y negociación devuelven, así, una imagen distante del absolutismo ibérico de control irrestricto descripto por Acemoglu, Johnson y Robinson, demostrando que el absolutismo como práctica política no era incompatible con la multiplicación y fortalecimiento de poderes corporativos descentralizados (Yun-Casalilla, 2019: 263, 264).

De esta manera, durante el siglo XVI el monarca había ganado capacidad para regular las relaciones sociales y hacer cumplir los compromisos mediante sus reglas (autopostulándose como árbitro para legitimar la defensa de sus propios intereses en el juego) (Yun-Casalilla, 2019: 237). Sin embargo, la pervivencia de un espacio jurídica y económicamente heterogéneo dio lugar a

2 En este sentido, Yun-Casalilla adopta con sentido heurístico la perspectiva schumpeteriana según la cual los sistemas impositivos ( $y$, consecuentemente, la movilización de recursos para la guerra) constituyen subproductos de la estructura social. Yun-Casalilla (2019: 155, 157).

3 Una concepción que remite, lateralmente, a la explicación ofrecida por Mokyr sobre los orígenes institucionales de la Revolución Industrial en la sociedad inglesa del siglo XVIII, y con la cual podría sostener un diálogo. Véase Mokyr (2008: 64-119). una pluralidad de pactos entre la corona y cada uno de sus reinos, afectando los costos de transacción en operaciones realizadas a través de sus fronteras políticas (Yun-Casalilla, 2019: 243). Recaía así en instituciones informales, tales como las familias y las redes de relaciones de afinidad, la articulación de mecanismos para reducir aquellos costos de transacción, aún allí cuando las instituciones formales atentasen contra ello (YunCasalilla, 2019: 255). Hacia 1600, las redes interpersonales y las distintas instituciones informales adquirieron un mayor margen de maniobra que el que detentaron hasta entonces respecto del poder del monarca y la expansión de esas redes globales en los territorios más distantes de la monarquía sirvió como canal para la transferencia de productos y la difusión de pautas culturales, y desde el primer cuarto del siglo XVII la relación entre el rey y las oligarquías urbanas comenzaría a atomizarse, desintegrando el carácter corporativo en concordancia con el sistema descentralizado (Yun-Casalilla, 2019: 286, $289,395)$. Ya hacia 1668 la península ibérica se encontraba, entonces, gobernada por un sistema en el cual las negociaciones entre la corona y las élites dejaban de canalizarse a través de corporaciones como las Cortes, acentuando una creciente tensión entre el rey y una miríada de actores sociales, (que perseguían a su vez intereses contradictorios), socavando el horizonte de crecimiento económico (Yun-Casalilla, 2019: 433).

América ocupa un rol medular en el esquema explicativo, integrándose en clave colonial al proceso de construcción del sistema imperial ibérico de largo plazo. En efecto, las remisiones del tesoro americano garantizaban los asientos concertados entre la corona y sus acreedores, brindándole al rey acceso a financiamiento con el respaldo de recursos cuyo gasto quedaba fuera del alcance de las Cortes (quienes, entre tanto, lograrían dar a las ciudades y corporaciones el control sobre otros recursos fiscales, como las alcabalas que garantizaban el servicio de deuda implicada en juros de largo plazo, que usualmente consolidaban deudas originalmente de corto plazo, contraídas mediante asientos). De este modo, el tesoro americano estaba en la base de lo que Yun-Casalilla identifica como una primitiva revolución financiera (que anticipaba aquella que terminaría de delinearse durante la segunda mitad del siglo XVII en Holanda para consolidarse en Inglaterra después de 1688), que permitió al rey contar con financiación a 
bajas tasas de interés (en efecto, los juros representaron el instrumento de deuda pública más barato de Europa durante el período) (Yun-Casalilla, 2019: 167, 169). Y cuando la deuda de Castilla comenzó a crecer más rápidamente que sus ingresos, la confiscación de las remesas particulares de riqueza americana se sumaban a préstamos forzosos, como acciones coactivas que la Corona empleaba no sólo para afrontar la bancarrota sino como puntapié para el inicio de un proceso de negociación con sus grandes acreedores (lo cual terminaría debilitando al sistema fiscal castellano desde el siglo XVI, dada la enajenación del patrimonio real y de su jurisdicción) (Yun-Casalilla, 2019: 173). El control del gasto quedaba así progresivamente en manos de una red de acreedores que tocaba Génova y América que operaba en ausencia de un sistema bancario, consolidando la descentralización de la administración de los recursos para la guerra en manos privadas de asentistas y acreedores que intervenían en función de sus propios intereses privados y desde las periferias de la monarquía compuesta (Yun-Casalilla, 2019: 193-194).

Esa descentralización tomaba forma asimismo en América: la importancia de los situados, destinados a transferir recursos entre distritos fiscales americanos, permitía a la corona descargar el costo de la defensa de sus territorios en la riqueza que éstos producían (Yun-Casalilla, 2019: 411). Y ello era posible en la medida en que dichos situados también representaban una fuente de beneficios económicos para los agentes locales involucrados en su movilización. La confluencia de intereses representada en esa negociación financiera condujo a una "renovación del pacto colonial con América" hacia el siglo XVII: los grandes comerciantes de ciudades neurálgicas, como Lima y México, terminarían de consolidar su autonomía mediante la obtención de privilegios que retroalimentaban su capital político, como contraprestación por la concesión de donativos y otros mecanismos de provisión de recursos a la corona (Yun-Casalilla, 2019: 409). ${ }^{4}$

Todo ello era posible, desde luego, gracias a una economía americana cuyo crecimiento se aceleró entre 1580

$4 \mathrm{El}$ rol de estos mecanismos de financiación en el Río de la Plata durante el siglo XVII puede consultarse en Wasserman (2016). Las implicancias de esos mecanismos financieros para la coordinación rioplatense de la defensa de los extremos meridionales en el contexto geopolítico del siglo XVIII, pueden observarse en véase Martínez y Wasserman (2020 en prensa). y 1630 gracias al ciclo minero y al desarrollo de economías de plantación orientadas a la exportación, lo cual dinamizó el comercio con la Península y, de igual modo, el contrabando (Yun-Casalilla, 2019: 362). La caída de remisiones de plata americana hacia Castilla a cuenta del rey entre 1600 y 1640 expresa, por lo tanto, la capacidad de retención de esas élites locales americanas, que a partir de las dificultades que la Hacienda del rey experimentaba para cubrir las necesidades generadas por la reanudación de la guerra en 1621 contaban entonces con una favorable correlación de fuerzas para negociar con el poder central la obtención de privilegios y retroalimentaron su autonomía (Yun-Casalilla, 2019: 367, 375). Por lo tanto (y en este punto el libro reabre el debate con los arquetípicos argumentos neoinstitucionalistas), el crecimiento que experimenta América hasta mediados de siglo XVII no deriva de instituciones formales que representaban un obstáculo, sino del desarrollo de un sector informal de la economía que producía creciente riqueza. Entre tanto, aquel crecimiento de la economía americana sólo era posible en última instancia a expensas de una creciente desigualdad y explotación de las mayorías (Yun-Casalilla, 2019: 414, 418). Tal como lo señala el autor, en América la sociedad ibérica demostró una capacidad sin precedentes para destruir ecosistemas, proceso ante el cual las instituciones ibéricas se demostraron ineficientes para reponer los recursos destruidos (Yun-Casalilla, 2019: 149).

La monumental obra de Yun-Casalilla recorre, de esta manera, el complejo y extendido proceso de globalización europea que durante la modernidad temprana protagonizaron los imperios ibéricos, atendiendo no sólo a la estructuración institucional de sus economías sino a la naturaleza culturalmente singular de esas instituciones, cuya justa ponderación requiere atender a sistemas de reglas y organizaciones reticulares no siempre formalizadas con arreglo a los dispositivos visibles del andamiaje político. Da cuenta de la importancia del capital político como factor que orientaba la racionalidad operativa de esas instituciones implícitas, así como de la capacidad que los actores de estas redes tuvieron para controlar de manera descentralizada la administración de recursos financieros de la corona, tanto en Europa como en América. Ello redundaba en un sistema que habría distado de condecirse con las tradicionales caracterizaciones absolutistas o con los modelos de estados fiscales-militares 
centralizados. Un sistema que durante ese largo plazo experimentó modulaciones en la construcción de consensos entre la corona y las élites locales, que el autor identifica como una de las claves explicativas del desempeño económico.

El cuidadoso desarrollo de cada una de sus hipótesis y una clara formulación de los interrogantes, establecidos en base a prolijos estados del arte, permiten advertir a sus lectores y lectoras la existencia de las discusiones historiográficas que pueblan cada uno de los capítulos del libro (volviendo a la obra no sólo una herramienta seminal para su campo de investigación sino, asimismo, un insumo bibliográfico para la enseñanza académica de los procesos históricos allí abordados y los debates historiográficos que los atraviesan). Y permite volver a pensar críticamente, desde la solidez de los datos empíricos y la erudita reposición de las variables socioculturales, los presupuestos y asunciones que permean la aproximación a este proceso clave para la comprensión de la economía global moderna.

\section{Referencias}

" Martínez, Carolina y Wasserman, Martín (2020 en prensa). “Estrategia imperial y crédito local. El archipiélago de Malvinas en la construcción de la frontera hispánica (1767-1774)", Revista de Indias.

" Mokyr, Joel (2008). The Institutional Origins of the Industrial Revolution. En Helpman, E. (Ed.), Institutions and Economic Performance. Cambridge: Harvard University Press.

"Wasserman, Martín (2016). "Real Situado y gestión patrimonial del recurso fiscal. Remesas para defensa del puerto de Buenos Aires en el siglo XVII", Nuevo Mundo, Mundos Nuevos, Mondes Américains.

"Yun-Casalilla, Bartolomé (2019). Iberian World Empires and the Globalization of Europe 1415-1668. Singapur: Palgrave Macmillan. 


\section{Esclavos e indígenas realistas en la Era de la Revolución. Reforma, revolución y realismo en los Andes septentrionales, 1780-1825}

Echeverri, Marcela (2018).

Bogotá: Universidad de Los Andes, Ediciones Uniandes.

\section{(4) Sergio Serulnikov}

Universidad de San Andrés-Conicet

En el tercer párrafo de su libro, Marcela Echeverri plantea al lector el siguiente dilema: "En una circunstancia notable en la historia de la esclavitud, los representantes de la monarquía española movilizaron a los esclavos contra sus amos, y los esclavos defendieron la monarquía que históricamente había promovido la esclavitud. Al mismo tiempo, los descendientes de la población nativa, que tres siglos atrás habían sido conquistados por la fuerza, defendieron su condición de vasallos y tributarios de la Corona española. En esta coyuntura sin precedentes, las gentes que hasta entonces habían sido objeto de la dominación imperial, se convirtieron en sus acérrimos defensores" (p. XVIII). Ese dilema, a cuya elucidación está dedicada la obra, resulta de particular relevancia puesto que, hasta hace no tanto, estábamos acostumbrados a pensar que fueron las movilizaciones populares en favor de la causa revolucionaria la única posible fuerza motriz detrás de las grandes transformaciones sociales ocurridas durante las guerras de la independencia. No cabe duda, desde luego, que los ejércitos patriotas que surcaron la geografía de los virreinatos del Río de la Plata y de la Nueva Granada, los focos de actividad insurgente en el Perú y el Alto Perú, las masas campesinas que se sumaron a los proyectos emancipadores de Miguel Hidalgo y José María Morelos en México o, saliéndonos del ámbito hispanoamericano, la población negra de Saint-Domingue que en 1804 acabó de un plumazo con la dominación francesa, el esclavismo y la economía azucarera de plantación, conmovieron de raíz las relaciones de poder que por siglos habían vertebrado la sociedad colonial. Lo que el excelente estudio de Echeverri argumenta es que no puede decirse lo contrario de aquellos que se alienaron con el bando realista. Bajo ciertas condiciones, también el monarquismo popular pudo operar como una formidable herramienta política de igualación.
El libro se centra en la provincia colonial de Popayán, un vasto territorio al sudoeste de Colombia que comprende los actuales departamentos de Cauca, Nariño y Valle de Cauca. Las comunidades indígenas estudiadas habitaban el distrito andino de Pasto y los esclavos trabajaban las minas de oro y las haciendas de las tierras bajas del Pacífico. Ambos grupos se unieron a las causa realista, primero en contra de las ambiciones expansionistas de la junta autonomista erigida en Quito en 1809 y, luego, entre 1822 y 1825, durante la resistencia a la invasión de las tropas de Simón Bolívar. Las razones de esta inconmovible fidelidad a la Corona, sostiene Echeverri, nada tuvo que ver con tendencias al conservadurismo o la existencia de una configuración ideológica que ha sido denominada, para variadas sociedades campesinas y de Antiguo Régimen, "monarquismo ingenuo". La incorporación de los indios a los ejércitos realistas tuvo una lógica eminentemente transaccional. A cambio de su crucial participación en el esfuerzo bélico, los pueblos andinos procuraron, y obtuvieron, una rebaja de los tributos, los beneficios asociados al servicio de las armas y el apuntalamiento de sus derechos de autogobieno comunal frente caciques ilegítimos, curas doctrineros, magistrados y otros miembros de las elites rurales. No eran ciertamente reivindicaciones novedosas puesto que, como muestra la autora, desde fines del siglo XVIII las comunidades desarrollaron una intensa actividad legal para defender sus percibidas prerrogativas socioeconómicas ante los tribunales coloniales. Lo que el contexto de profunda crisis imperial a escala Atlántica y regional posibilitó, fue canalizar esas demandas mediante su involucramiento en las conflagraciones con las fuerzas patriotas que, desde 1808 , fueron emergiendo al sur y al norte del bastión realista de Popayán.

En el caso de los esclavos devenidos en soldados, su objetivo fue simple y taxativo: la emancipación. No difirieron 
al respecto de esclavos en otras áreas de América Latina y el Caribe que procuraron lo mismo abrazando el republicanismo. Así, por ejemplo, en 1811 los esclavos en dos minas, Yurumanguí y San Juan, anunciaron en los siguientes términos que se sumarían a la causa realista en oposición a la decisión de sus propietarios, quienes se habían rebelado contra el gobernador de Popayán: "Ellos, que en tanto eran esclavos en cuanto sus amos habían sido vasallos del Rey, que los amparaba y dispensaba su real protección cuando la imploraban contra la sevicia y crueldad con que los trataban, no debían continuar en su dominio y servidumbre sino gozar de la misma libertad que los vasallos fieles con subordinación únicamente a su majestad y a sus ministros, bajo cuyo dominio y autoridad protestaban permanecer" (p. 141). El mensaje no podía ser más transparente: la condición de esclavitud no era absoluta, estaba supeditada a la protección que el monarca les proporcionaba frente a los abusos de poder de sus dueños; la movilización militar en defensa de sus derechos soberanos los tornaba vasallos libres de la Corona como el resto de la población hispánica o indígena. Por lo demás, la referencia al amparo del rey ante las violencias de sus amos no era meramente abstracta. Los esclavos africanos o afro-descendientes habían por décadas empleado los estrados judiciales para protestar contra sus duras condiciones de vida y de trabajo, y la promulgación por parte de la administración borbónica en 1789 de la Instrucción sobre la educación, trato y ocupaciones de los esclavos intensificó esta práctica al codificar su debido tratamiento y reafirmar la potestad de los magistrados regios para supervisar la relación entre las partes, fuera en minas, plantaciones o haciendas. Aunque la legislación fue vigorosamente resistida por los dueños de esclavos, apuntaló la creencia de estos últimos acerca de sus derechos como sujetos de la Corona (pp. 78-82).
Mientras contábamos ya con ricos trabajos sobre el potencial transformador de la movilización de los grupos subalternos en favor de la causa realista durante las guerras de la independencia en Perú, México o Cuba, la investigación de Echeverri sobre la Nueva Granada tiene la virtud de incorporar en una misma inquisición a indios y esclavos, dos grupos poblacionales que tradicionalmente han sido objeto separado de análisis. ${ }^{1}$ Y lo lleva a cabo de manera sistemática a lo largo de la obra. A su vez, el acertado recorte temporal 1780-1825 permite trazar las raíces históricas de las prácticas políticas colectivas que vamos a ver emerger durante la etapa final del dominio español en América. Así pues, el volumen se abre con un panorama general de Popayán y Nueva Granda durante todo el período bajo examen, para luego alternar, en orden cronológico, entre capítulos dedicados a las comunidades andinas de Pasto y a los esclavos de las tierras bajas del Pacífico, sin perder nunca de vista los lazos que anudaron ambos procesos. El volumen se cierra con una reconstrucción y análisis del impacto de la incursión de los ejércitos bolivarianos en Popayán.

Señalaría, finalmente, que mientras el estudio (publicado originalmente en inglés y magníficamente traducido al español por Silvia Rivera Cusicanqui) descansa en un exhaustivo relevamiento de fuentes primarias dispersas en archivos de varios países, y presenta por tanto una gran riqueza empírica, se nutre asimismo de una voluminosa literatura teórica y comparativa en torno a temáticas tales como las formas de acción colectiva de las clases subalternas, el esclavismo, el monarquismo popular y la llamada era de las revoluciones atlánticas. Sus contribuciones, por consiguiente, exceden el campo de la historia novogranadina y colombiana. Especialistas en otras regiones y períodos encontrarán abundante material de interés en sus páginas.

1 Méndez, C. (2014). La república plebeya. Huanta y la formación del Estado peruano, 1820-1850. Lima: Instituto de Estudios Peruanos; Guardino, P. (2009). El tiempo de la Libertad. La cultura política popular en Oaxaca, 1750-1850. Oaxaca: Universidad Autónoma Benito Juárez de Oaxaca; Childs, M. D. (2006). The 1812 Aponte Rebellion in Cuba and the Struggle against Atlantic Slavery. Chapel Hill: University of North Carolina Press. Para distintas instancias de monarquismo popular en el mundo atlántico, véase el reciente dossier "Monarchy, Empire, and Popular Politics in the Atlantic Age of Revolutions", Varia Historia, vol. 35, n. 67, 2019. 


\title{
San Martín. Una biografía política del libertador
}

\author{
Bragoni, Beatriz (2019).
}

Buenos Aires: Edhasa, 336 páginas.

\section{0}

Alejandro Pautasso

Instituto de Historia Argentina y Americana "Dr. Emilio Ravignani"-UBA/Conicet, Argentina

San Martín. Una biografía política del libertador tiene como virtud ir más allá de lo que uno podría esperar encontrar dentro del género biográfico, puesto que presenta un equilibrio en la narración entre el personaje y la sociedad de su época, operando ambos como elementos insoslayables en el análisis y las explicaciones que Bragoni vierte a lo largo del libro. La autora logra narrar la biografía política de San Martín desde una mirada que toma distancia de los relatos y las hagiografías clásicas que relatan su vida a partir tanto de los resultados de su accionar como desde su representación mítica y heroica. Para ello, presta particular atención al problema, no menor para la escritura de este género, de la relación entre la acción individual y las condiciones históricas. Los contratiempos presentes en otras biografías, donde el sujeto vertebrador del relato parece doblegar o trascender su contexto, se diluye en la argumentación del libro gracias a que San Martín es situado como un actor histórico que debe lidiar con los conflictos, incertidumbres y contingencias de su tiempo.

Al momento de restituir las coyunturas históricas que atraviesa el protagonista, el libro evidencia la incorporación de renovadas y heterogéneas perspectivas historiográficas que habilitan a pensar los dilemas y comprender las dificultades que se suscitaban en el telón de fondo de la escena histórica, pero que tenían una injerencia en la vida de San Martín. En primer lugar, se retoman las hipótesis, interrogantes e investigaciones que gravitan alrededor de la historiografía política de los procesos revolucionarios hispanoamericanos, las trayectorias de las soberanías independientes y las ingenierías institucionales. Estas indagaciones permiten enmarcar las tensiones entre republicanismo y monarquía, centralización y descentralización, orden y revolución; dilemas presentes en el viaje americano de San Martín. En segundo lugar, incorpora los nuevos análisis dentro de los estudios de la guerra, habilitando a pensar el componente social e identitario de las fuerzas militares, la logística de los recursos, el rol de las jerarquías y el peso de los antagonismos en las filas militares. Esto construye una mirada sobre el cuerpo militar que resquebraja una imagen monolítica, para destacar las gestas, dinamismos y grietas. Por último, se observa la atención a la literatura sobre el género biográfico que Bragoni tiene en consideración al momento de recomponer la vida de San Martín, que, por un lado, le permite problematizar la relación entre el cambio histórico y los elementos subjetivos del accionar individual, y, por el otro, pensar en escribir la vida del individuo con una perspectiva crítica que elude caer en la justificación retrospectiva del personaje.

San Martín, si bien es el sujeto que estructura el relato, no monopoliza las páginas del libro. Esto se refleja en el heterogéneo repertorio de fuentes históricas a las que recurre Bragoni. Entre estas se incluyen epistolarios, prensa, proclamas, oficios, crónicas, memorias y biografías relativas a un amplio elenco de sujetos. Además, el corpus documental trasciende la territorialidad americana, incorporando relatos de viajeros y documentación europea, lo que termina por construir el perfil de un San Martín con dimensiones atlánticas. Este exhaustivo aparato erudito que sirve de cimiento para la biografía expone la experiencia de Bragoni como historiadora, pues posee los condimentos necesarios para apelar al universo de los especialistas, pero sin por ello excluir a un público más amplio. De esta manera, el libro despliega un exitoso balance entre rigor académico y divulgación.

En cuanto al contenido del libro, el mismo ofrece no sólo la reconstrucción de la trayectoria sanmartiniana, tanto en su experiencia militar y política como en su pensamiento, sino también un análisis sobre el proceso de construcción y transformación de la memoria y el uso público de su figura luego de su fallecimiento. Los ocho capítulos que conforman el volumen, pueden dividirse 
en tres momentos. El primero, que abarca los primeros cuatro capítulos, están dedicados a seguir a San Martín en su trayectoria política y militar entre España y América. Se traza el itinerario que lo sitúa primero en Cuyo, luego conduce al lector a la liberación de Chile, para finalizar con la institucionalización del Protectorado en el Perú. En este seguimiento, se exponen las estrategias y avatares en el tejido y erección de su autoridad militar y política. Cierra esta primera instancia del libro con la entrevista de Guayaquil entre Bolívar y San Martín.

El segundo momento se compone por los capítulos quinto y sexto en los cuales se recupera la trayectoria del protagonista en su "ostracismo voluntario", vertebrándose sobre la preocupación sanmartiniana que se mecía entre el juicio histórico que se conformaría sobre su recuerdo y el potencial olvido. Por último, en los capítulos siete y ocho Bragoni repone la trama de la historia de los usos públicos, los relatos, la mitología y hagiografía que se erigieron alrededor de San Martín, desde su muerte hasta el presente, ensayando una respuesta a la inquietud sanmartiniana por el juicio de la posteridad. En ese recorrido, la autora analiza no sólo las narrativas erigidas por personajes como Bartolomé Mitre y Ricardo Rojas, sino también las interpretaciones que hicieron algunos gobiernos y partidos políticos, como el peronismo, los nacionalistas, y los revisionistas. Esta historización logra hilar de modo inteligente, cohesivo y crítico una minuciosa reconstrucción por la laberíntica trama de los usos públicos de la figura del Libertador.

A lo largo del libro Bragoni analiza hipótesis, interpretaciones y problemas que han pesado y girado alrededor de la figura de San Martín y su tiempo. Sin pretensión de exhaustividad, a continuación, se expone una selección de los que se consideran más relevantes. En primer lugar, respecto de los sentidos e interpretaciones que se han brindado sobre la desobediencia de San Martín al Directorio en la coyuntura de su caída, Bragoni repone exhaustivamente las piezas documentales del año 1820. El análisis la lleva a sostener que la decisión del héroe de Chacabuco estuvo guiada por su intención de proseguir con la campaña del Perú, antes que, por ejemplo, con una supuesta afinidad por el sistema federal.

Esto abre la puerta a un segundo núcleo problemático: la defensa de la monarquía en la práctica y el pensamiento del Libertador. La preferencia por un sistema de gobierno con un fuerte poder central se construye en la narrativa como una combinación de las lecturas y la experiencia que lejos está de agotarse en una afinidad por una forma de gobierno en términos idealistas o doctrinales que tenía por modelo la monarquía constitucional británica. La reconstrucción de los avatares y el devenir de las guerras y las revoluciones van moldeando este posicionamiento, que opera como respuesta pragmática a la preocupación por el desorden y la anarquía en coyunturas donde nada está dado. Asimismo, la concentración del poder era considerada una herramienta necesaria para afianzar las victorias y obtener los resultados deseados en la conformación de las nuevas comunidades políticas. Este pensamiento y preferencia política no fue etéreo. San Martín lo puso en práctica cuando se erigió como Protector del Perú, instancia en la que concentró el mando político y militar, provisoriamente, hasta que se Ilamase al Congreso Constituyente. Estas predilecciones y acciones le valieron no pocas críticas por parte de sus contemporáneos.

En relación a la famosa, pero no menos enigmática, entrevista de Guayaquil entre Bolívar y San Martín, la autora reconstruye los diferentes trazos que dejan los protagonistas, las narraciones históricas y la mitología. En este proceso, se confronta la historia con la construcción de la memoria, siempre selectiva, iluminando ciertos espacios, y dejando otros en las sombras. En el proceso de la reconstrucción de las distancias y desacuerdos entre Bolívar y San Martín, destacan dos interpretaciones. Por un lado, la imposibilidad de unir las fuerzas militares pues la genealogía, las experiencias y las identidades forjadas al calor de las batallas hacían emerger las disidencias entre los cuerpos militares al mando de cada líder. Por el otro, las formas de gobierno que cada uno defendía en el concierto de las emergentes comunidades políticas, donde Bolívar apostaba por la república, mientras que San Martín por la monarquía constitucional, tornando poco probables una unión entre ambos.

Un cuarto elemento que se pone en juego en la biografía es la indeterminación y contingencias que se desarroIlan en el periplo del protagonista en interacción con un contexto signado por la inestabilidad. Esta lectura queda expuesta con ejemplaridad en los balances que 
Bragoni realiza respecto a las victorias en los campos de batalla de Chile y Perú, y la edificación de la autoridad cuyana. Lejos de significar el orden y la paz, estas instancias abrían juegos que dejaban un sabor amargo: luchas intestinas entre las facciones políticas y conflictos al interior del cuerpo militar - tanto por falta de pago de salarios, cuestiones de identidad y/o debilitamientos en la cadena de mando.

En un balance, la autora presenta una biografía política que posee la virtud de no agotarse en la vida de San Martín, sino que incorpora los sinuosos caminos de los relatos, las mitologías y la simbología póstuma que se construyeron alrededor de su persona. La perspectiva crítica que Bragoni acerca al lector presenta un San Martín que se acerca más a un sujeto mortal que tiene que lidiar con los conflictos, dilemas, amarguras y felicidades como efecto de sus elecciones y las condiciones de su contexto, distanciándose de la imagen hagiográfica y mitológica que lo canoniza como héroe moral y nacional. De esta manera, al retomar e hilar la realidad histórica de San Martín y las diversas ficciones e interpretaciones que sobre él se proyectaron y continúan persistiendo en el presente, Bragoni resuelve el desafío de escribir una vida que persiste abierta e inconclusa. 


\title{
Historia de la vejez en la Argentina (1850-1950)
}

\author{
Otero, Hernán (2020).
}

Rosario: Prohistoria, 240 páginas.

\section{$(1)$}

María Silvia Di Liscia

Instituto de Estudios Históricos y Sociales de La Pampa, CONICET-Universidad Nacional de La Pampa, Argentina.

Si fuera posible, Otero ha vuelto a sorprender con esta nueva obra, escrita en varios y simultáneos registros a la vez, que demuestran su habilidad como demógrafo y sus evidentes capacidades en la historia y la literatura. ${ }^{1}$ No es que sea inesperado que un investigador pueda construir mensajes en diferentes claves, sino que éstas lleguen a tan buen fin, sin soslayar la labor estadística comparativa o dar relieve a la sutileza de las letras de tangos.

El tema, en sí mismo, es signo de singularidad y actualidad. La historización de la salud, de los sectores populares, de las mujeres, del trabajo, de las emociones y tantas otras posibilidades ha dejado, sin embargo, huecos en otras áreas. Tales vacancias no son siempre evidentes pero es real que de las variables clásicas de clase, género y edad, quizás la más pobremente considerada sea esta última y de ella, la vejez tiene indudablemente un menor interés entre los investigadores, mientras que la infancia o la juventud acumulan multitud de aportes anualmente. También tenemos presente que no se haya recuperado en toda su centralidad a los ancianos como actores sociales en, por ejemplo, las historias sobre sentimientos como la soledad, producto de la imposibilidad real de los contactos más cercanos o en estudios sobre las enfermedades crónicas -propias de este grupo etario-. Y que tengan escasa visibilidad las mujeres ancianas en los avances sobre movimientos sociales de enorme significación, como las Abuelas de Plaza de Mayo.

El afán de extender un análisis hacia todo un país y en el lapso de un siglo es un reto del cual el libro sale bien situado, sobre todo en tiempos donde cunde una

1 Decimos esto por sus aportes anteriores, de gran riqueza analítica. Ver Otero, H. (2006). Estadística y Nación. Una historia conceptua del pensamiento censal en la Argentina moderna 1869-1914. Buenos Aires. Prometeo Libros; y Otero, H. (2012). Historia de los franceses en la Argentina. Buenos Aires: Biblos. extrema especialización y el desarrollo de estudios locales concentrados en pocos años. Tal éxito es posible porque plantea ejes con notoria claridad expositiva, demostrando la solidez de los argumentos, con una cronología de 100 años de la vejez argentina. La apertura es paralela a la organización estatal y aparición de series estadísticas. El cierre se corresponde con la percepción y acción de políticas públicas específicas del peronismo, como la legislación que involucra la jubilación y el nacimiento de una nueva especialidad médica, la gerontología, todo lo cual sucede en los años cincuenta del siglo $\mathrm{XX}$.

La obra busca combinar simultáneamente las dimensiones de análisis que involucran a "los viejos, la vejez y el envejecimiento" a través de tres partes que recorren esa centuria, ensambladas de manera armónica y con variedad de fuentes y documentación histórica. Así, las secciones remiten a la "comprensión histórica de la vejez, (la mortalidad, el trabajo, la incidencia y distribución de la población anciana), las políticas de la vejez (hospitales, asilos y jubilación) y, por último, las representaciones y saberes que dieron origen al nacimiento de la vejez, es decir a su irrupción en la agenda social, política y cultural a mediados del siglo XX" (p. 22).

Es significativo que Historia de la Vejez encuentre su inspiración en dos obras muy diferentes: por un lado, la de Alejandro Bunge, reconocido economista conservador quien en 1940 alertaba con pronósticos catastróficos sobre la reducción demográfica futura y el aumento de la proporción de ancianos. Por otro, la de Simone de Beauvoir, famosa escritora de un país envejecido, como lo era Francia hacia 1970. Tales elecciones nos permiten a su vez encuadrar el surgimiento de la visión de "urna" respecto a las pirámides demográficas argentinas y entrever cómo el envejecimiento es una problemática filosófica occidental que excede las interpretaciones 
nacionales. Y ponen sobre el tapete que la "tercera" edad (o cuarta), es siempre un actor ignorado porque sus movilizaciones no tienen la épica requerida para alimentar una historia de logros y conquistas, y está teñida y superpuesta a la pérdida de la salud, a la aparición de nuevas incapacidades, a la desaparición laboral y finalmente, a la invisibilización social.

El texto rompe con algunos presupuestos, por ejemplo, el mito de la excepcionalidad argentina respecto del aumento rápido de la esperanza de vida al nacer y a su vez, de la prolongación de la vida similar a los países europeos o de inmigración masiva. Los indicadores demográficos permiten afirmar al autor que Ecuador o Uruguay lograron ese fenómeno antes o contemporáneamente. Los logros argentinos estaban muy por debajo de Francia, pionero en la transición demográfica, y también de Canadá y Estados Unidos, países que como Argentina incorporaron población extranjera.

Las aproximaciones comparativas son útiles para indicar el comportamiento demográfico que el autor también desgrana en relación a una problemática interesante, la de la geografía regional de la vejez. El mapa argentino aparece así con sustanciales diferencias, producto de las migraciones ultramarinas con el arribo de varones jóvenes. La consecuente transformación del perfil demográfico posterior explica en parte sus variaciones seculares.

Las representaciones sobre la senectud en el siglo XIX y XX referían tanto a patriarcas o matriarcas dominantes entre las familias encumbradas y mostraban su contracara, es decir, los ancianos abandonados entre los sectores más pobres. A través de la literatura y la música popular se exploran en el libro las vidas de los pocos hombres y mujeres que pasaban la línea de los sesenta años y arribaban con un bagaje de experiencias y bienes para pasar con cierto confort el último lapso de vida, rodeados de hijos y nietos. O bien, los relatos cargados de ansiedad sobre el destino en los asilos de aquellos sin posibilidades propias o recursos familiares. En el campo o la ciudad, la complejidad de la problemática sobre esta población casi intangible adquiere tanto individualidad como incorporación estadística, en un doble juego tanto micro como macrohistórico.

Geronte, viejo, anciano, tercera o cuarta edad son formas de referir a lo que en otros momentos era una esperanza, desbaratada a veces por la imposibilidad de previsión y un entorno social hostil. Pero ahora es ciertamente una sentencia de muerte o (quizás peor), de olvido. Hoy en día esa etapa indica, en una sociedad predominantemente viejicida y filojoven las desventajas laborales, físicas, psíquicas y mentales. Una más alta esperanza de vida ocasiona, paradójicamente, la incertidumbre, inquietud que anima la lectura de esta obra. Sin aventurar pronósticos difíciles de comprobar, con un sólido bagaje argumentativo e interrogantes de riqueza conceptual, el texto nos permite comprender la conformación histórica de la vejez. Al exponer sobre los viejos de ayer, también es una especie de conjura, no mágica sino analítica, sobre los terrores sobre nuestro propio futuro. 


\section{Los planes quinquenales del peronismo. Objetivos, prioridades y financiación}

Gomez, Teresita (2020).

Buenos Aires: Lenguaje Claro. 351 páginas.

\section{ه Daniel Santilli \\ Universidad de Buenos Aires, Argentina}

Hace casi 15 años Claudio Belini y Marcelo Rougier (2006) plantearon que desde mediados de la década del '90 se estaba produciendo un cambio de criterio en la mirada aplicada al período peronista, dejando de lado la imagen construida desde sus resultados para estudiar los procesos desarrollados en el período. Desde ese entonces, se han profundizado los estudios sobre el lapso, abarcando diferentes aspectos, como el proceso político, la relación con el movimiento obrero, la política económica, las fuerzas armadas, y la sociedad en su conjunto. Se han conformado redes, programas, congresos, seminarios etc. en diversos centros de estudios, focalizando la cuestión regionalmente. Pero por sobre todo ha prevalecido una mirada profesional, menos prejuiciosa sobre la etapa, si bien los avances no han sido parejos en todos los campos mencionados. Por ejemplo, uno de los aspectos aún a profundizar es el de la economía y, dentro de ella, una cuestión relevante es la de la planificación. En este sentido se destacan aportes de P. Berrotarán (2003), A. Jáuregui (2005), C. Belini (2014), los recientes libros de G. de la Vega (2017) y H. González Bollo y D. Pereyra (2019), entre otros textos más generales que aludieron a la planificación.

El libro que nos ocupa se inserta en esa saludable renovación historiográfica, incorporando un estudio que hasta ahora no había sido muy revisado, salvo por Jauregui (2005): la evaluación del origen y aplicación de los fondos en los sucesivos planes quinquenales que el peronismo pergeñó. Si bien se ha avanzado mucho en los fundamentos teóricos y políticos de la planificación peronista, así como sus inicios, intenciones y sus dificultades, las cifras han sido poco estudiadas

El texto rastrea los comienzos de la planificación en Argentina remontándose al momento en que el Estado intervino en la economía, a partir de las consecuencias de la Gran Depresión de 1929. Y concluye con su abrupta supresión, como la concebía el peronismo, derogando el segundo plan quinquenal durante la revolución libertadora de $1955 .^{1}$

En doce capítulos, la autora relata este aspecto de la historia económica de nuestro país desde 1914 hasta 1955. Introduce en los primeros apartados el concepto de planificación en la teoría, y discurre así entre los aportes teóricos acerca de la intervención del Estado en la economía y del grado de la misma, y los debates que se avivan a partir de las consecuencias de la Primera Guerra mundial, hito que marca las transformaciones que están operando en el seno del Estado. Pero los efectos de la gran depresión, empujado además por la experiencia de Francia, Inglaterra, Alemania y Estados Unidos, a más de la Unión Soviética, indujeron a adoptar algún tipo de planificación.

El capítulo 3 se enfoca en la historia nacional y en los mecanismos que se pondrán en funcionamiento para superar ese momento particular. Es el bautismo del Estado como actor, interviniendo para modificar conscientemente efectos económicos. El abandono del laissez faire se inicia en 1933, con medidas denominadas intervencionismo defensivo (Berrotarán, 2003), propuestas por el ministro Federico Pinedo; se implementan juntas reguladoras para la comercialización externa de productos agropecuarios y se funda el Banco Central de la República Argentina. Un antecedente del plan, frustrado en el Congreso, que el mismo ministro presentará en 1940.

1 Sin embargo la planificación no desapareció hasta mediados de la década de 1970 (González Bollo, 2015) 
Este plan resultó un precedente para desarrollar el Consejo Nacional de Posguerra, que concitó el trabajo de técnicos y el aporte teórico de diversos intelectuales. $\mathrm{EI}$ organismo surgió pensando en las secuelas económicas de la Segunda Guerra Mundial (De la Vega, 2017). El capítulo cinco analiza este organismo, cuyo mayor aporte fue la recopilación de datos y el ejercicio del debate sobre la situación social y el ordenamiento económico social. La llegada de Perón al poder abrió paso a un Estado intervencionista con una fuerte impronta industrialista, apoyada en el desarrollo del mercado interno.

Los capítulos siete y ocho se ocupan del Primer Plan Quinquenal, 1947/51, presentado en el Congreso ocho meses después de las elecciones que consagraron a Perón como Presidente de la Nación. El plan era relativamente elemental y se basaba en la imagen optimista de la situación económica argentina que tenía Perón. Sus objetivos eran desarrollar el mercado interno, mejorar la situación de los pobres mediante el pleno empleo, elevar la renta nacional y fortalecer el Estado. Se presupuestó una erogación de $m \$ \grave{n} 6.000$ millones, de los cuales el $80 \%$ se utilizaría para desarrollos energéticos y obras para mejorar estructuras de transporte, vial, ferroviario y aéreo. La ley que concedió los fondos incluyó inversión en salud pública (10\%) y en educación universitaria (3\%). Finalmente el monto se multiplicó por tres al cabo del quinquenio debido a que se realizaron erogaciones que, si bien previsibles, no habían sido presupuestadas. Gómez menciona que resulta difícil deducir el origen de los recursos; de todos modos pudo determinar que los aportes provinieron del IAPI, del BCRA, de créditos bancarios y de los resultados de las mismas inversiones. Un significativo $24 \%$ se invirtió en la producción agropecuaria. Pero la baja de producción del sector agrícola, generador de divisas, puso en crisis el sistema restando posibilidades de importación. Se sumaron condiciones externas, como el proteccionismo alimentario de Europa, acompañado por el deterioro de los términos del intercambio y razones políticas.

Se hizo necesario un plan de emergencia (capítulo 9), que implicaba un aumento de los saldos exportables por incremento de la producción y disminución del consumo, el fomento del ahorro popular, y la reducción de importaciones. Se cambió el eje del discurso oficial en
1952; de la redistribución a la productividad, del consumo al ahorro.

Superada la crisis, se elaboró el Segundo Plan Quinquenal, 1953-1957. El eje sería la acción de los privados coordinada por el Estado, bajando el perfil intervencionista. El plan estuvo mejor estructurado que el anterior, porque estimó el crecimiento del PBI, sobre el cual se calculó el monto a invertir. La inversión en la acción económica que incluía lo que se denominó "vuelta al campo" un apoyo a la producción agropecuaria y su mecanización, un $43 \%$ destinado al comercio y las finanzas, manteniendo convenios bilaterales para la exportación, incluyendo países limítrofes con manufacturas, mientras que el $4 \%$ sería otorgado a acción social. Los recursos provendrían de la emisión de títulos colocados en un $50 \%$ en las cajas de jubilaciones; el resto se financiaría con la explotación de las obras ejecutadas. Más adelante se convocó al capital extranjero, mediante una controvertida ley específica. El plan quedó trunco debido al golpe de Estado de septiembre de 1955. Gómez considera que las perspectivas económicas y sociales avizoraban un buen resultado, pero "requería consolidar determinadas alianzas y reformular otras", acuerdos que no se concretaron, atribuyendo el fracaso relativo a aspectos políticos, antes que económicos; el PBI se incrementó en 1953 y 1954, y en 1955 se lograría un crecimiento del 7\%. Un resultado fundamental para los tiempos por venir fue el fortalecimiento del Estado como actor fundamental.

En resumen, el libro aporta datos que sirven para proseguir con el destierro de visiones estereotipadas, como la desatención del sector agrícola, dado que tanto en el primer plan como en el segundo los aportes fueron equivalentes entre industria y "campo", en coincidencia con las nuevas miradas que describí en el primer párrafo. Otra paradoja que conviene profundizar es el escaso monto destinado a la acción social, construcción de viviendas, salud pública, hospitales, etc, que sin embargo fue suficiente para darle vida a un movimiento político que una vez derrocado logró pervivir y volver al gobierno 18 años más tarde.

\section{Referencias}

" Belini, C. (2014). Inflación, recesión y desequilibrio 
externo. La crisis de 1952, el plan de estabilización de Gómez Morales y los dilemas de la economía peronista. Boletin del Instituto de Historia Argentina y Americana Dr. Emilio Ravignani(40), 105-148.

" Belini, C., \& Rougier, M. (2006). Los dilemas de la historiografía económica sobre el peronismo: certezas dudosas, vacíos persistentes. Aportes para la construcción de una agenda de investigación. En J. Gelman (comp.), La historia económica argentina en la encrucijada. Balances y perspectivas (págs. 351-369). Buenos Aires: Prometeo.

"Berrotarán, P. (2003). Del plan a la planificación. El Estado en la época peronista. Buenos Aires: Imago Mundi.

" De la Vega, G. (2017). Planificar la Argentina justa, libre y soberana: El Consejo Nacional de Posguerra (1944-1946). Bernal: UNQ.

" González Bollo, H. (2015). Exploraciones sobre la Argentina planificada. Anuario IEHS(29\&30), 119-124.

" González Bollo, H., \& Pereyra, D. (2019). Estado y planificación en el lejano sur: agencias y funcionarios de la Argentina peronista (1944-1955). Bernal: UNQ.

" Jáuregui, A. (2005). La planificación económica en el peronismo (1945-55)". Prohistoria, IX(9), 15-40. 